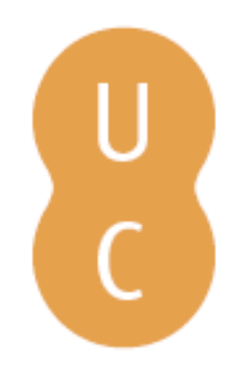

\title{
pommalina
}

\section{A presença de Paulo Freire na América Latina: notas sobre a relação Ivan Illich e} Paulo Freire

\author{
Autor(es): $\quad$ Silva, Gildemarks Costa e
}

Publicado por: Imprensa da Universidade de Coimbra

URL

persistente: URI:http://hdl.handle.net/10316.2/41296

DOI: $\quad$ DOI:https://doi.org/10.14195/978 $\quad$ D89 26 1326-0_7

Accessed : $\quad$ 26-Apr-2023 10:42:52

A navegação consulta e descarregamento dos títulos inseridos nas Bibliotecas Digitais UC Digitalis, UC Pombalina e UC Impactum, pressupõem a aceitação plena e sem reservas dos Termos e Condições de Uso destas Bibliotecas Digitais, disponíveis em https://digitalis.uc.pt/pt-pt/termos.

Conforme exposto nos referidos Termos e Condições de Uso, o descarregamento de títulos de acesso restrito requer uma licença válida de autorização devendo o utilizador aceder ao(s) documento(s) a partir de um endereço de IP da instituição detentora da supramencionada licença.

Ao utilizador é apenas permitido o descarregamento para uso pessoal, pelo que o emprego do(s) título(s) descarregado(s) para outro fim, designadamente comercial, carece de autorização do respetivo autor ou editor da obra.

Na medida em que todas as obras da UC Digitalis se encontram protegidas pelo Código do Direito de Autor e Direitos Conexos e demais legislação aplicável, toda a cópia, parcial ou total, deste documento, nos casos em que é legalmente admitida, deverá conter ou fazer-se acompanhar por este aviso.

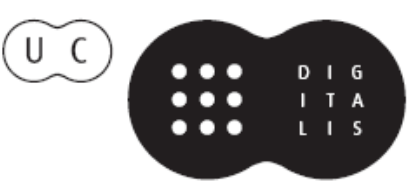




\section{A PRESENCGA DE PAULO FREIRE NA AMÉRICA LATINA: NOTAS SOBRE A RELAÇÃO IVAN ILLICH E PAULO FREIRE}

Gildemarks Costa e Silva ${ }^{17}$

\section{Resumo}

Neste artigo, abordamos, embora de forma exploratória, a presença de Paulo Freire na América Latina, especialmente a partir de sua interação com o CIDOC (Centro Intercultural de Documentação) e, consequentemente, com Ivan Illich. Temos por objetivo refletir sobre a relação entre Paulo Freire, Ivan Illich e CIDOC, tendo em vista compreender qual foi a contribuição do CIDOC para a constituição e internacionalização do pensamento de Freire. Argumentamos que a participação de Freire nesse centro contribuiu para a constituição e divulgação do seu pensamento. Finalmente, levantamos a hipótese de que essa mesma internacionalização talvez esteja na origem do afastamento teórico de Illich em relação ao pensador pernambucano.

17 Professor da Universidade Federal de Pernambuco.

Este trabalho foi desenolvido com o apoio do Centro de Educação e do Departamento de Fundamentos Sócio Filosóficos da Educação Universidade Federal de Pernambuco, e do grupo de Pesquisa Crítica da Tecnologia e Educação. 


\begin{abstract}
This paper addresses, although in an exploratory way, the presence of Paulo Freire in Latin America, specially his interaction with CIDOC (Centro Intercultural de Documentação - Intercultural Center of Documentation), and, consequently, with Ivan Illich. We aim to reflect on the relationship between Paulo Freire, Ivan Illich and CIDOC, in order to understand what was the contribution of CIDOC to the establishment and internationalization of Freire's thinking. Finally, we present the hypothesis that this internationalization might be at the origin of the theoretical distance between Illich and the intellectual from Pernambuco.
\end{abstract}


O que aqui se oferece é somente um folheto próprio Marte, propriis auspiciis, próprio stipendio [...]. (Søren Kierkegaard. Migalhas Filosóficas).

Por isso, o mundo de Freire e de Illich foi necessariamente um mundo distorcido; um prisma distorcido como o único mundo possível para transformar a distorção do mundo do establishment do sistema, que se considera a si próprio normal. (Carlos Alberto Torres. Os mundos distorcidos de Ivan Illich e Paulo Freire).

Neste artigo, abordamos a presença do pensamento de Paulo Freire na América Latina, especialmente a partir de sua interação com o CIDOC e, consequentemente, com Ivan Illich. De modo especial, objetivamos examinar a relação entre Paulo Freire, Ivan Illich e CIDOC, tendo em vista compreender qual foi a contribuição do CIDOC para a constituição e internacionalização do pensamento de Paulo Freire. Argumentamos que a participação de Freire nesse centro contribuiu para a constituição e divulgação do seu pensamento. Compreendemos que isso se dá, fundamentalmente, em função de que no CIDOC há uma reapropriação criativa dos movimentos da década de 60 , e, nesse centro, se expressa de forma candente o Volksgeist latino-americano dessa época, relacionado à transgressão da institucionalização, à utopia política, bem como à criatividade de pensamento.

Procuramos explorar, nas considerações finais, a ideia de que essa mesma internacionalização do pensamento de Paulo Freire se encontra no cerne do distanciamento de Ivan Illich em relação ao pensador pernambucano. De acordo com Ivan Illich, o pensamento do autor de Pedagogia do Oprimido sofre um processo de "colonização" por parte dos "marxistas cristãos" instalados no Conselho Mundial das Igrejas, os quais desejam fazer de Freire um "intelectual/ídolo" latino-americano, o que será um significativo equívoco e um motivo para afastamento entre ambos. 
Este artigo é composto das seguintes partes: a) inicialmente, delineamos o que representou o CIDOC, quando procuramos demarcar as origens e características do mesmo. Na sequência, b) exploramos os movimentos sociais e intelectuais que caracterizam o volksgeist latino-americano da década de 60, o qual encontra no CIDOC eixo de articulação e recriação do mesmo; c) em um terceiro momento, nos concentramos na caracterização da presença de Paulo Freire no CIDOC, sua relação com Ivan Illich e da importância disso para a constituição e divulgação do seu pensamento. Nas considerações finais, abordamos o distanciamento - no campo teórico - entre Ivan Illich e Paulo Freire.

\section{O Centro Intercultural de Documentação - CIDOC}

O CIDOC (Centro Intercultural de Documentação) foi fundado por Ivan Illich e colaboradores em 1961, em Cuernavaca, próximo a cidade do México, tendo sido extinto em 1976. De acordo com Lemmerer (2009), o CIDOC era uma conjunção de Escola de Línguas, Editora e Centro de Pesquisa, cujo foco inicial foi a preparação de missionários católicos dos Estados Unidos e do Canadá que se dirigiam, de forma voluntária, para a América Latina. De um modo geral, o centro pretendia dar a conhecer a realidade latino-americana e, ao mesmo tempo, permitir a preparação para atuação pastoral nessa realidade. Para Jean Robert (2013), inicialmente, Ivan Illich procurou organizar em Cuernavaca o CIF (Centro Intercultural de Formação), cuja meta central era formar religiosos para o trabalho na América Latina (Robert, 2013). "El proyecto se asemejaba al de los voluntários para el Papa, una versión católica de algo parecido al Peace Corps" (Robert, 2013, p. 1). De um modo geral, o CIF possibilitava aos estudantes aulas de espanhol, inclusive com aprendizagem por meio de "imersão" em famílias mexicanas, uma biblioteca e seminários sobre a realidade latino-americana (Robert, 2013). 
Illich, contudo, tinha críticas ao papel e aos objetivos do CIF, pois percebe que as propostas externas de desenvolvimento poderiam interferir muito pouco na realidade da América Latina, visto que essa assistência iria fazer, para ele, as pessoas se sentirem dependentes e inferiores (Robert, 2013; Lemmerer, 2009). Ao mesmo tempo, em 1968, a Congregação para a Doutrina da Fé convida Illich para ir a Roma responder algumas questões, muitas delas sobre colegas e amigos (Robert, 2013). Illich '[...] recomendó al 'inquisidor' dirigirse mejor a los interessados y declaró no estar dispuesto a contestar ninguna pregunta que no fuera especificamente sobre él. Se rompieron las relaciones entre el CIF y la jerarquia romana" (Robert, 2013, p. 2).

Após esse processo, Ivan Illich decide abandonar o Sacerdócio e, ao mesmo tempo, o CIF deixa de existir (Robert, 2013). Illich "[...] pidió al papa que lo relevara de todos sus privilégios sacerdotales" (Robert, 2013, p. 2). No seu retorno a Cuernavaca, em conjunto com seus amigos, envolve-se na organização do CIDOC. Nesse novo centro, há a busca da independência econômica, e a Escola de Línguas passa a ter uma importância fundamental (Robert, 2013).

Com esse novo perfil, torna-se um centro de pensamento, sem professores, sem alunos, tendo como tema central pensar alternativas ao modelo de desenvolvimento da América Latina. Em função disso, rapidamente se torna um atrativo para intelectuais e políticos considerados de vanguarda de todo o mundo. Como escreve Torres (2005, p. 88):

Este Centro, sob a inspiração de Illich, influenciado pelas ideias de Raymond Everett e com a presença de um sem número de intelectuais radicais, nos quais se incluem Paul Goodman, Erich Fromm, Peter Berger, o bispo de Cuernavaca (vinculado à teologia da libertação), Sérgio Mendez Arceo e o próprio Paulo Freire, que viajou do Chile, converte-se num lugar obrigatório para o estudo e para a prática de educação revolucionária no mundo inteiro. 
Zaldivar (2012) constata que o CIDOC se constitui em um espaço sui generis, "[...] cujo objetivo era documentar as transformações no campo da cultura, da política, da religião, da tecnologia e da educação que estavam acontecendo nos anos sessenta na região da América Latina”. Também Marcelo Gajardo (2010) confirma que "desde o ano de sua criação até meados da década de 70 do século $\mathrm{XX}, \mathrm{o}$ CIDOC foi um lugar de encontro de numerosos intelectuais [...] que refletiam sobre os problemas da educação e da cultura". Ainda sobre isso, Lemmerer (2009) ressalta que o CIDOC se constituiu em um "[...] instituto educacional e de pesquisa para a exploração de alternativas. Tornou-se um imã para os intelectuais enfants terribles, do educador Brasileiro Paulo Freire ao importante pensador Americano dos 1960 Paul Goodman" (Lemmerer, 2009, p. 5).

Ao mudar o perfil, o centro se torna, portanto, um espaço parauniversitário que, além de uma excelente biblioteca e da organização de cursos de espanhol, proporcionava oficinas sobre temas sociais e políticos (Gajardo, 2010). Ivan Illich organizava seminários que se voltavam a pensar alternativas institucionais para a sociedade latino-americana. Além disso, o "[...] CIDOC se volverá la 'mayor editorial mexicana en términos de títulos publicados anualmente', publicando principalmente sobre temas relacionados con los predicamentos de la sociedad industrial" [...] (Robert, 2013, p. 3). Entre os temas centrais, estão aqueles denominados de "vacas sagradas" da modernidade, quais sejam: a) a educação; b) os serviços de transporte; c) os sistemas de saúde (Mitcham, 2002; Illich, 2008). No que concerne aos objetivos deste texto, convém mencionar que a educação foi um dos focos de análise do CIDOC e também especialistas da educação de diferentes partes do mundo circularam por esse centro tendo em vista pensar meios educativos que promovessem uma aprendizagem a partir dos diferentes momentos da vida.

No ano de 1976, após as ideias de Ivan Illich passarem por um significativo processo de propagação, é tomada a decisão de 
encerrar as atividades da instituição (Robert, 2013). Para Robert (2013), em termos oficiais, a deliberação é comunicada em função de um suposto "excesso de êxito", porém, internamente, o CIDOC fechou por que "[...] había dado lo que había de dar y era tempo de hacer otra cosa" (Robert, 2013, p. 4).

De fato, nas palavras do próprio Illich, o principal motivo para o CIDOC encerrar as atividades reside no fato de que aquilo que se desejava obter, inicialmente, já tinha se realizado. Como assevera o autor: "en 1973 llegué a la conclusión de que todo lo que deseaba conseguir cuando inaugure el centro en 1960, o cuando lo reforme en 1966, todo lo que siempre quice hacer y que podia hacer ya se había hecho" (Illich, 2013). Além disso, contudo, Illich pontua outros elementos que, certamente, pesaram nessa importante decisão. Primeiro, o próprio fato de que o contexto da América Latina na década de 1970 se tornava bastante perigoso para quem se envolvia em um centro como o CIDOC. Parece que a imagem que o centro possuía na América Latina na década de 1970 e o "[...] riesgo para la seguridad física de mis colaboradores se había vuelto algo sobre lo que ya era difícil assumir la responsabilidad" (Illich, 2013, p. 164).

Além desses elementos mencionados, certamente, os riscos de institucionalização acadêmica do centro também influenciaram no encaminhamento de encerramento das atividades, principalmente caso se leve em consideração às críticas de Ivan Illich aos limites da institucionalização. De acordo com Illich (2013, p. 164) "grupos de docentes de Stanford, Cornell y de otras universidades querían asumir el control del puesto". Para Illich, os "experts internacionais" tentaram assumir o lugar de um conjunto de pessoas que, inicialmente, se dedicaram a construção do CIDOC e que não possuíam diplomas, nem sequer havia - em alguns caos - certificação de estudos básicos.

Além disso, Illich também menciona o fato de que a valorização da moeda mexicana culmina por ameaçar a autonomia financeira do ins- 
tituto, visto que o curso de línguas, embora com valor elevado para o México, representava valor extremamente baixo para os Estados Unidos.

La independencia del CIDOC se basaba en la diferencia de los sueldos entre Estados Unidos y México: oferecíamos cursos intensivos para el aprendizage de la lengua - cinco horas al día durante cuatro meses en grupos de três - y pagábamos a estudiantes de los liceos mexicanos sueldos que como professores de liceo en Cuernavaca no hubieran podido cobrar jamás. Aplicábamos tarifas que resultaban altas en México, pero extremamente bajas en los Estados Unidos. De este modo, por médio de economías de escala, conseguíamos lo necesario para sacar adelante el instituto y la biblioteca". (Illich, 2013, p. 165)

A questão central a se colocar nesta parte - e que nos interessa neste texto - é sobre o que pode ter motivado o êxito do CIDOC. Para Robert (2013), no cerne desse sucesso, é necessário situar o "espírito da época”, qual seja, o espírito de contestação de 1968, que passou por um processo de reapropriação criativa por parte de Ivan Illich, seus colaboradores, enfim, pelo CIDOC. Assim, pensando em termos de América Latina, não é temerário propor que esse "espírito da época" da década de 60 estava bem presente no CIDOC e que, nesse centro, ele passou por um processo de reapropriação criativa e desenvolvimento conforme os movimentos intelectuais e sociais da América Latina, visto que um dos objetivos centrais do CIDOC remetia a pensar um modelo alternativo de desenvolvimento para os países da região.

\section{Volksgeist latino-americano}

Ivan Illich era, antes de mais nada, um pensador que se situava em um contexto histórico específico, qual seja, "[...] o dos anos 60 
do século XX - período caracterizado por uma crítica radical da ordem capitalista e de suas instituições sociais, notadamente da escola" (Gajardo, 2010, p. 11). A respeito desse contexto da América Latina, Torres (2013) constata que a América Latina se constitui, no período, um verdadeiro "caldo" de cultivo de uma nova sociedade, levando ao surgimento de perspectivas radicais de transformação social. Para o autor, a década de 60 está na origem de projetos espetaculares e explosivos, em que se fazia presente seja na possibilidade de uma transformação individual, seja de uma revolução (Torres, 2005). Trata-se de um fenômeno que ocorre em praticamente todo o mundo, sendo vivenciado, inclusive, na América Latina, onde se torna um significativo centro de cultivo de uma nova sociedade (Torres, p. 83).

Apoiando-se na leitura que Marcuse faz do termo Volksgeist em Hegel, em que este termo está associado "a espírito de uma nação, a sua história, a sua religião e o grau de participação política”, Torres (2005) propõe, em termos de América Latina, que o seu Volksgeist, nesse período, está diretamente ligado "[...] à revolução e à transgressão das normas estabelecidas, assim como à criatividade crítica no pensamento, à inovação na ciência, na tecnologia e à utopia política" (Torres, 2005, p. 83). Nesse sentido, é possível pensar que o CIDOC expressa de forma candente esse Volksgeist latino-americano. Aliás, expressa e se torna o centro catalizador do mesmo, permeando, dessa forma, a constituição do pensamento e das relações Illich e Freire. "[...] Illich e Freire, quem sabe se inconscientemente, conceberam sob diferentes perspectivas teóricas uma ideia similar de mudança social radical. Essa noção de mudança radical assentava num conjunto de teorias e orientações filosóficas, bem como teológicas, em voga na altura e que marcaram o espírito da época - um espírito ousado, libertário e criativo" (Torres, 2005, p. 83).

Ainda de acordo com Torres (2005), a origem desse Volksgeist não está somente nas tradições ricas e antigas das muitas das culturas milenares do continente, mas em contribuições acadêmicas 
de "teorias que procuravam explicar e transformar a realidade" (Torres, 2005). Assim, talvez não seja temerário afirmar que esse Volksgeist exerce forte influência nas ideias e ações de Illich e Freire. Influência essa que, de acordo com Torres (2005), ocorre a partir de quatros grandes movimentos intelectuais e sociais.

No que concerne aos movimentos intelectuais, para Torres (2005), é fundamental olhar, primeiro para as críticas aos modelos de desenvolvimento, muito especialmente a teoria da dependência. Ela foi

[...] estabelecida no âmbito da academia chilena nos anos 1960, com a publicação do livro, considerado clássico, de Fernando Henrique Cardoso e Henzo Falleto - Dependencia y desarrollo en América Latina -, que se expandiu como um barril de pólvora por todo o continente, articulando uma das maiores críticas sistemáticas ao modelo tradicional econômico e social e, por conseguinte, ao próprio capitalismo subdesenvolvido e, em menores dimensões, às teorias da democracia. (Torres, 2005, pp. 83-84)

Mesmo sem desconhecer a importância de outras reflexões críticas nessa época, como as da CEPAL, e de teóricos como Pablo González Casanova, Rodolfo Stavenhagen, entre outros, Torres (2005) considera a teoria da dependência fundamental nesse processo, uma vez que articula uma crítica aos modelos tradicionais de desenvolvimento econômico e social.

O fato é que, de um modo geral, tais movimentos intelectuais procuraram explicar o "[...] subdesenvolvimento latino-americano, a exploração e o colonialismo interno da região" (Torres, 2005, p. 84). Além disso, Torres (2005) lembra a simbologia, tanto em vida quanto na morte, da figura revolucionária de Ernesto "Che" Guevara e do seu discurso em 16 de agosto de 1961, no Conselho Interamericano Econômico e Social. No período de 6 a 17 de agosto de 1961, realiza-se em Punta del Este, Uruguai, a reunião do Conselho Interamericano 
Econômico e Social. A reunião contou com a presença dos principais líderes da América Latina e focou nas políticas de desenvolvimento para a América Latina. Ernesto "Che" Guevara, em seu discurso, demarca forte rejeição ao modelo de desenvolvimento americano, conforme delineado na "Aliança para o Progresso".

Além desse primeiro elemento mencionado, Torres (2005) apresenta um segundo elemento relacionado aos movimentos intelectuais, que é a constituição, por parte de um conjunto de filósofos latino-americanos de uma "nova perspectiva filosófica denominada Filosofia da Libertação”. Entre esses filósofos, Torres (2005) destaca a figura do filósofo, teólogo e historiador Henrique Dussel.

Este modelo filosófico, elaborado a partir de uniões analíticas de corte fenomenológico e existencialista, mas incorporando a visão do pensamento marxista, questiona as noções de alteridade na racionalidade ocidental e procura incorporar as noções das culturas tradicionais latino-americanas, como opção para a articulação de um modelo civilizacional mais racional e generoso que o modelo europeu etnocêntrico, racista e autocentrado, assim como auto-celebratório (Torres, 2005, pp. 84-85).

Assim, essa nova perspectiva filosófica contava com o tema da verdade, da autenticidade e do "ethos" latino-americano entre os seus princípios (Torres, 2005).

Podemos, agora, focar em um terceiro elemento que conforma esse Volksgeist latino-americano. Para Torres (2005), é necessário compreendermos a importância da teologia da libertação nesse contexto dos anos 60, e como ela conforma tanto a vida quanto a teoria de Freire e Illich. A teologia da libertação, enquanto elemento importante nesse Volksgeist, apontou para um modelo de igreja que tem como pressuposto a "opção preferencial pelos mais pobres". Isso em um contexto em que a institucionalização da Igreja envolvia 
a construção de uma instituição que se apresentava ao lado das classes dominantes. Esse pressuposto da teologia da libertação era um verdadeiro "[...] zénite e lugar de origem da atividade religiosa das igrejas populares ou comunidade de base" (Torres, 2005, p. 85).

Finalmente, em relação ao Volksgeist latino-americano do período, a educação popular tem um papel fundamental. Necessitamos destacar que o próprio Freire será, como observa Torres (2005), um dos expoentes dessa emergência da educação popular no contexto latino-americano. A respeito da importância da educação popular nesse contexto, Torres (2005) destaca que se trata de "[...] um modelo que nascendo originalmente na Espanha, com inspiração socialista e anarquista com impulso para a educação massiva da classe operária, se transfere para a América Latina como um modelo para educação dos setores populares" [...]" (Torres, 2005, p. 85).

Assim, esses quatro movimentos demarcam, de acordo com Torres, as influências que configuram esse Volksgeist latino-americano dos anos 60. Tais movimentos também demarcam um Volksgeist diretamente relacionado à transgressão das normas estabelecidas, à utopia política, bem como a criatividade do pensamento (Torres, 2005). Finalmente, mencionamos, a partir de Torres (2005) que esse Volksgeist não é exclusivo da América Latina. De fato, na sua análise, o autor aponta que, até mesmo no embalo do manifesto anarquista Imagine lançado por Lenin, nos anos 1960, em diferentes partes do mundo, foram identificados movimentos revolucionários, novas invenções que desafiavam a imaginação, além da busca da paz através de novas emoções. Por fim, convém mencionar que cremos que esse Volksgeist encontra no CIDOC eixo de articulação e recriação do mesmo, influenciando fortemente a constituição do pensamento de Freire e de Illich, visto que permeava a relação entre ambos a partir do envolvimento deles com o CIDOC.

Como demarca Gajardo (2010), desde o ano de sua criação até 1976, o CIDOC é um espaço para articulação e encontro de vários 
intelectuais americanos e latino-americanos, embora, eventualmente, com a presença de intelectuais europeus. Ao debaterem os problemas da cultura e da educação, esses intelectuais tinham na figura de Ivan Illich alguém sempre presente. O próprio Illich coordenava pessoalmente os diversos seminários. "São dessa época os famosos debates apaixonados entre Paulo Freire e Ivan Illich sobre a educação, a escolarização e a conscientização, assim como os diálogos entre Illich e outros especialistas da educação [...]" (Gajardo, 2010, p. 13).

Por isso, compreendemos que, de alguma forma, o CIDOC se constituiu em um eixo aglutinador e articulador desses movimentos intelectuais e sociais, o que culmina em forte influência na conformação do pensamento de Paulo Freire e Ivan Illich. Lembramos que eles

[...] alcançaram a glória dos grandes iconoclastas da educação, pregando ora a conscientização ora a desescolarização, como alternativas aos mitos e rituais conservadores de uma educação bancária e autoritária. Os seus pensamentos ultrapassaram as fronteiras e converteram-se numa mensagem mundial. (Torres, 2005, p. 86)

De fato, também para Lemmerer (2009), como o CIDOC se constituiu em um espaço de atração de inúmeros intelectuais, políticos e pensadores de diversas partes do mundo, é crível supor que, uma vez no CIDOC, tal situação permitiu a expressão e reapropriação criativa dos movimentos sociais e intelectuais mencionados antes. E, nesse caso, é possível pensar que Illich e Freire, enquanto expoentes intelectuais desse processo, tenham sido influenciados por tal situação.

Ainda referindo-se especificamente ao pensamento de Illich, Lemmerer (2009) argumenta que

[...] sem essa rede social, muito do seu influente pensamento jamais teria emergido. Nos quinze anos de funcionamento do 
centro (1961 a 1976), vários grandes pensadores da filosofia e teologia, dos estudos culturais, história, teoria educacional e economia de diferentes lugares do mundo utilizaram-se do espaço institucional do centro como um local de encontros". (Lemmerer, 2009, p. 6)

Nesse sentido, para Lemmerer (2009), o CIDOC se constitui no ambiente ideal para análises e trocas de perspectivas sobre as controvérsias em relação aos diferentes temas e problemas da América Latina no período. Nesse caso, compreendemos que isso ocorre porque no CIDOC se expressa de forma candente o Volksgeist latino-americano da década de 60.

\section{Ivan Illich, o CIDOC e Paulo Freire}

A relação de Freire com o CIDOC é precedida pelo encontro entre Ivan Illich e Paulo Freire no Brasil. Como escreve o próprio Illich: "Paulo y yo nos conocimos no Brasil a princípios de los sessenta" (Illich, 2013, p.166). Isso ocorre em viagem de Illich ao Brasil para a fundação de um centro similar ao CIDOC na cidade de Petrópolis, no Rio de Janeiro. Este centro de Petrópolis foi dirigido por John Vogel, e o próprio Illich foi o seu primeiro estudante, quando de seu estudo da Língua Portuguesa ${ }^{18}$ e da realidade brasileira. Tal centro teve, nas próprias palavras de Illich (2013, p. 167) um "[...] papel singular e importante antes y después del acenso de los militares al poder. Yo mismo acudí allí para aprender português: fui el primer estudiante".

${ }^{18}$ É fato notório que muito jovem Ivan Illich tinha fluência em vários idiomas. Ao longo de sua vida, continuou a estudar várias línguas e, de acordo com Torres (2005), o autor da tese da desescolarização da sociedade tinha o domínio em, pelo menos, 25 idiomas, entre as quais algumas línguas orientais. 
Quando dessa viagem ao Brasil, Helder Câmara ${ }^{19}$, conhecido internacionalmente por sua contribuição na constituição da teologia da libertação, torna-se o tutor de Illich por aproximadamente um período de 45 dias. Enquanto metodologia de trabalho, Dom Hélder Câmara, que segundo o próprio Illich foi o seu tutor mais exigente, solicitava que Illich fizesse a leitura de pelo menos um livro de um autor brasileiro por dia. Nas palavras de Ivan Illich (2013, p. 167): "cada día me hacía ler al menos un libro de un autor brasileño, o sobre la obra de un autor de tal nacionalidad".

Após a leitura do livro, normalmente no período da tarde, havia encontros programados entre Dom Hélder Câmara, Illich e o autor do texto lido. Isso com a finalidade de "[...] conversar durante horas de Brasil, de su política, de sus géneros literários o de sus diferentes mentalidades" (Illich, 2013, p. 167). Além disso, Dom Hélder Câmara demandou que Illich fizesse viagens - parte significativa delas por meio de ônibus - por diferentes regiões do Brasil, para, dessa forma, conhecer adequadamente a realidade brasileira. É justamente nesse momento de conhecimento da realidade brasileira e de leituras de autores brasileiros que se efetiva o encontro de Illich com Freire. Como Illich afirma (2013, p. 167): "bien, uno de los hombres que tenía que encontrar era Paulo Freire. Enseguida congeniamos y nos hicimos buenos amigos".

Aproximadamente ano e meio depois desse encontro ocorrido no Brasil - e Illich já de retorno ao México - os militares brasileiros levaram Freire para a prisão. Provavelmente por meio de Dom Hélder Câmara, Illich tomou conhecimento da prisão. Sobre essa detenção, Illich escreve (2013, p. 167): "al día seguiente fui a ver Teodoro Moscoso, quien había sido uno de los cinco membros del Consejo para la Instrucción

19 Dom Helder Câmara, arcebispo Emérito de Olinda e Recife. Um dos fundadores da Conferência Nacional dos Bispos do Brasil. Teve forte influência na teologia da libertação. 
Superior en Puerto Rico, donde yo había trabajado. Lo conocía muy bien". Nessa época, Teodoro Moscoso trabalhava como administrador da "Aliança para o Progresso", e Illich solicitou-lhe para que intercedesse em favor da "salvação" de dois pernambucanos, tanto Paulo Freire quanto Francisco Julião ${ }^{20}$. Sobre esse encontro, contudo, Illich é avisado por Teodoro Moscoso que a CIA "[...] le había informado de que esos dos eran tan peligrosos como Castro! No pregunté el porqué: con esse tipo de personas no puedes ir muy lejos" (Illich, 2013, p. 167).

O fato é que Freire, após a saída da prisão, se aproxima de Illich, do CIDOC e de Cuernavaca. Como o CIDOC também funcionava como editora, é publicado e editado nesse centro o primeiro livro de Paulo Freire fora do Brasil. Sobre esse período, Ivan Illich relembra (2013, p. 167): "entonces me llevé a Paulo conmigo a Cuernavaca y allí editamos y publicamos su primer libro fuera de Brasil". Em síntese, no CIDOC, há as primeiras traduções dos escritos de Paulo Freire. Além disso, há esforço especial por busca de abertura e consolidação de canais de circulação de textos do autor para diferentes partes do mundo. É como se constata no seguinte depoimento de Illich (2013, p. 167): "se tradujeron por primera vez sus escritos a varios idiomas y los difundimos por todo el mundo".

Ao que parece, a relação intelectual entre os dois, permeada pelo CIDOC, se torna intensa. Podemos lembrar, por exemplo, que no manifesto lançado por Illich intitulado Sociedade sem Escolas, ele relata que tal documento é, em muito, fruto dos debates ocorridos nas quartas-feiras pela manhã no CIDOC, e Paulo Freire é então referenciado entre os que mais contribuíram para os debates com críticas e sugestões (Illich, 1970). E mais, nesse mesmo manifesto Sociedade sem Escolas, Illich, ao analisar o medo que a escola propaga em relação a ideia de que é possível aprender algo sem

20 Francisco Julião Arruda de Paula, nasceu em Pernambuco, em 1915. Foi advogado, político e líder das Ligas Camponesas no Engenho Galileia. 
a dependência da institucionalização, aponta que experiências de alfabetização então desenvolvidas por Paulo Freire eram devidamente debatidas e analisadas por ele e demais membros do CIDOC.

Algumas passagens do próprio manifesto Sociedade sem Escolas demostram que Illich ficou bastante impressionado com as experiências desenvolvidas por Paulo Freire. Ele relata, por exemplo, ter observado que muitos dos participantes desses momentos cresciam em consciência social enquanto aprendiam a ler e escrever. Como ele próprio demarca (1970, p. 34)

parecia que tomavam a realidade em suas mãos quando escreviam-na no papel. Lembro-me de um homem que se queixava do pouco peso do lápis: era difícil manejá-lo porque não pesava tanto quanto uma pá; lembro-me também de outro que no caminho para o trabalho parou com seus companheiros e escreveu no chão, com a enxada, a palavra que haviam discutido: água.

Lemmerer (2009), em pesquisa desenvolvida na Universidade Viena - conforme mencionamos antes-, examina de forma mais pormenorizada essa cooperação acadêmica ocorrida em torno do CIDOC. Baseando-se em uma abordagem de "análise de redes sociais", ao se concentrar nos 15 anos de funcionamento do instituto - de 1961 a 1976 -, a autora demonstra que, entre os vários pensadores de diferentes partes do mundo que mantiveram laços acadêmicos com o CIDOC, Paulo Freire foi uma das presenças mais marcantes.

$\mathrm{Na}$ figura a seguir, retirada de Lemmerer (2009, p. 15), está expresso o resultado dessa análise em relação ao quantitativo de cooperação científica estabelecida em torno do CIDOC. A rede exposta na figura abaixo foi montada pela autora levando em consideração não apenas as publicações nos cadernos do CIDOC, mas fundamentalmente a presença física em Cuernavaca, especialmente evidências de participação nos seminários e debates ocorridos nesse centro. 
Apresentamos, então, a figura retirada de Lemmerer (2009, p. 15):

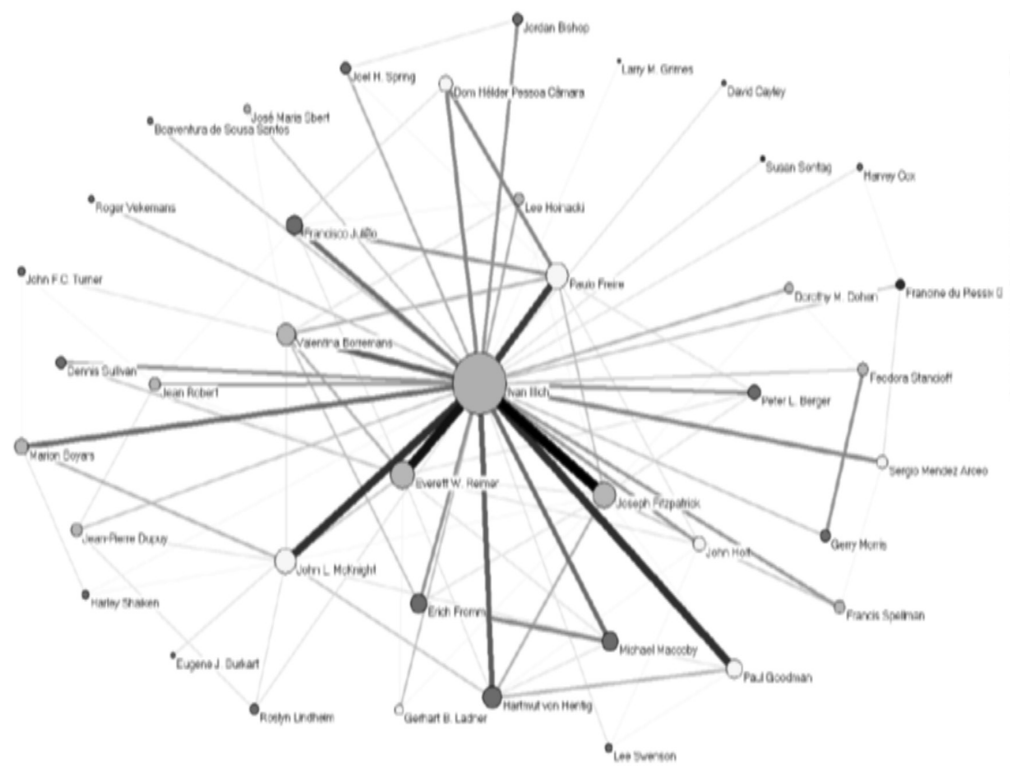

Como é possível identificar, a figura anterior contém quatro cores diferentes junto ao nome dos atores, indicando o tipo de relação que foi estabelecido com o CIDOC, nesse caso com Illich, visto que é difícil separar a relação entre ambos. Dito de outro modo: cada cor representa o tipo de relação estabelecido por aquela pessoa com Illich (Lemmerer, 2009). A cor marrom representa relações e contatos estabelecidos no âmbito institucional; a cor vermelha demonstra contatos eventuais, esporádicos, enquanto que a cor laranja representa aquelas pessoas que seguiram Ivan Illich ao longo da vida; os representados nesta cor laranja são aquelas pessoas consideradas "illichianas". Finalmente a cor amarela representa uma cooperação entre os mais próximos, amigos e conhecidos de Ivan Illich. É justamente com essa cor que está referenciado o nome de Paulo Freire, portanto ele está identificado como aqueles que possuíam relação mais próxima e amiga. 
$\mathrm{Na}$ figura anterior, que mostra a quantidade de cooperação acadêmica ocorrida, a linha mais forte ilustra uma quantidade maior de cooperação estabelecida entre o ator, Ivan Illich e o CIDOC. Quanto mais espessa a linha, maior a cooperação acadêmica identificada por Lemmerer (2009) entre os dois polos da linha. Por outro lado, quanto mais fina a linha, menos cooperação foi identificada pela pesquisadora entre os dois polos da linha, ou seja, entre o referido ator e Illich/CIDOC. Nesse caso, Paulo Freire está inserido entre um dos atores mais importantes dessa rede, com laços extremamente fortes entre ele e o CIDOC.

Em síntese, e em referência a questão delineada antes do Volksgeist latino-americano, não e temerário enfatizar que o mesmo se manifestou de forma candente no CIDOC, conforme enfatizamos. Além dos demais aspectos teóricos mencionados antes sobre a natureza e funcionamento do CIDOC, consideramos adequado destacar -, conforme se observa na figura apresentada da pesquisa desenvolvida por Lemmerer (2009) -, a enorme presença de intelectuais, políticos e pensadores com significativa penetração nos problemas da época, tais como: Erich Fromm, Paulo Freire, Ivan Illich, Paul Goodmann, John Holt, Hélder Câmara, Everth Reimer entre outros.

No manifesto mencionado antes, "Sociedade sem escolas", Illich dá testemunho dessa interação. Ele próprio debita significativa parte de suas ideias e do manifesto às contribuições dos diversos membros que frequentavam o CIDOC e os seus seminários. Como escreve o autor (Illich, 1970, pp. 14-15):

[...] submeti as diversas partes desse livro aos participantes de nosso programa CIDOC, em Cuernavaca. Vários deram sugestões e teceram críticas. Muitos reconhecerão idéias suas nestas páginas, sobretudo Paulo Freire, Peter Berger e José Maria Bulnes, mas 
também Joseph Fitzpatrick, John Holt, Angel Quintero, Lauman Allen, Fred Goodman, Gerhard Ladner, Didier Piveteau, Joel Spring, Augusto Salazar Bondy e Dennis Sullivan. Entre meus críticos, Paul Goodman, principalmente, obrigou-me a rever meu modo de pensar.

Embora não seja aspecto a ser explorado neste artigo, Freire não é referenciado como um dos seus críticos. Tanto é assim que, após citar as diversas contribuições, Illich, dá destaque, entre os seus críticos, apenas a Paul Goodman. Em todo caso, retomando a discussão anterior e em função daquilo que delineamos antes, consideramos que não é sentido apontar que esse processo contribuiu, de forma significativa, para a constituição do pensamento de Paulo Freire e de sua crítica radical a educação. Mais uma vez, buscamos suporte em Torres (2005) quando enfatiza que

os quatros grandes movimentos sociais e/ou intelectuais que acolheram o trabalho de Paulo Freire (teoria da dependência, filosofia da libertação, teologia da libertação e educação popular) têm uma raíz nítida e cristalizada na América Latina e não deve surpreender que tenha servido de plataforma para articular as ideias de Freire [...]. (Torres, 2005, p. 90)

Essa influência pode ser melhor dimensionada caso se considere que o CIDOC, como referenciado antes, está atrelado ao desenvolvimento de um pensamento crítico sobre educação, desenvolvimento e modernidade na América Latina e se tornou - assim compreendemos - o eixo catalizador e recriador desses quatro movimentos intelectuais e sociais, especialmente a partir da circulação expressiva de um conjunto de intelectuais e ativistas sociais nas diversas atividades do centro. 


\section{Considerações finais}

Neste texto, abordamos, mesmo que de forma exploratória, a presença de Paulo Freire na América Latina, especialmente a partir de sua relação com o CIDOC e, consequentemente, com Ivan Illich. De modo especial, objetivamos refletir sobre a relação entre Paulo Freire, Ivan Illich e o CIDOC, tendo em vista compreender qual foi a contribuição do CIDOC para a constituição e internacionalização do pensamento de Paulo Freire. Nestas considerações finais, procuramos responder a seguinte questão: em que consistiu o afastamento de Illich em relação a Freire?

Não houve distanciamento pessoal, visto que, como assinala o próprio Illich (2013), a amizade entre ambos sempre permaneceu intocável. Contudo, do ponto de vista teórico, há sinais tanto em Freire quanto em Illich de significativo afastamento entre ambos. É comum encontrarmos referências em textos dos dois pensadores a partir de certo período - em que cada qual se dirige ao outro de forma extremamente dura. Freire, por exemplo, em uma pergunta sobre a desescolarização, faz referências a Illich que ilustram o distanciamento (Torres, 2005). Abaixo, as palavras de Freire:

Neste momento, há certos pensadores e apelos científicos sociais dedicados à educação, que questionam todo o sistema educativo insistindo, efetivamente, que não vale perder tempo a investigar este sistema que tem de ser reformado, porque os produtos que estão a expelir são produtos que na realidade deformam em vez de roformá-lo. Da pergunta que faz se chega a Ivan Illich, a quem faço uma crítica. Indiscutivelmente, Ilich é um homem genial. Nos próximos cinquenta anos, um historiador da cultura ou da educação vai a ter de dizer que Illich existiu, indubitavelmente. Contudo, não é preciso esperar cinquenta anos para fazer uma crítica fundamental a Illich. Quando ele coloca todo o problema da desescolarização, 
no meu ponto de vista cai num erro. Ele nega-se constantemente a discutir a questão ideológica, e é precisamente por esta razão que não pode alcançar, na minha perspectiva, a totalidade do fenômeno que analisa. (Freire, Paulo cit. por Torres, 2005, p. 92).

Também na obra de Illich, é possível encontrar fragmentos em que o autor se refere às ideias de Freire com significativa hostilidade. Vejamos, por exemplo, a seguinte nota de rodapé de "El Género Vernáculo", quando menciona a origem do termo "conscientização":

El llamado "processo de civilización" se pone en marcha gracias a outro desarrollo, que se puede denominar de la 'concientización'. Este término fue acuñado en Brasil para designar una espécie de formación política de los adultos que buscaba que se responsabilizaran de sus propios assuntos, instrución organizada principalemente por sacerdotes que popularizaron las categorias marxistas com el propósito de ayudar a los pobres a descobrir que son humanos. (Illich, 2008, p. 314)

Ainda sobre esse afastamento, Ivan Illich confirma que do ponto de vista teórico houve, a partir de um certo momento, profunda divisão entre ele e Paulo Freire. Como escreve Illich (2013, p. 168):

La educación adulta además intenta expandirse y volverse obligatoria. Era esto lo que deseaba analizar de manera realmente crítica, así que, a pesar de la validez de sus opiniones, me alejé del enfoque del que Paulo se había vuelto el portavoz más eminente a lo largo de los años sessenta y princípios de los setenta, no solamente en América Latina, sino en todo el mundo. (Illich, 2013, p. 168)

Esse distanciamento de Illich em relação a Freire não deve ser interpretado, evidentemente, no sentido "tolo" de alguém que 
passa a simplesmente ser opositor do outro ou mesmo em função de intrigas políticas, visto que ambos permaneceram bons amigos. A questão que de fato implica apontar é sobre por que motivo Illich, após ter tomado o pensamento de Paulo Freire como significativo ponto de passagem para sua análise dos processos de escolarização, ritualização e institucionalização da educação, afasta-se completamente do autor de "Pedagogia do Oprimido".

Parece que esse rompimento se expressa especialmente a partir do momento em que Freire se torna consultor do Conselho Mundial das Igrejas, visto que, após esse período, poucos foram os momentos de interação entre ambos. Um dos últimos debates mais intensos entre os dois, ocorreu em 1974, em Genebra, quando se procurou aproveitar a visita de Illich a Suiça para a celebração do $50^{\circ}$ (quinquagésimo) Aniversário da Escola Internacional de Genebra, e houve a organização de um seminário entre ele e Freire. Esse evento culminou na publicação do livro Diálogo Paulo Freire-Illich, publicado em 1975 e que contou com as contribuições, além das de Freire e Illich, de William B. Kennedy, Heinrich Dauber e Michael Huberman. Nessa publicação, é possível observar o quanto ambos estão em caminhos diversos em relação ao mesmo objetivo de transformação da realidade.

Um indício que talvez ajude a esclarecer o afastamento teórico desses dois significativos pensadores críticos e radicais nos é apontada pelo próprio Ivan Illich, ao defender que os cristãos-marxistas instalados no Conselho Mundial das Igrejas tomaram a Paulo Freire como um ídolo e manipularam a imagem dele (Illich, 2013).

Sobre sua relação com Freire, Ivan Illich escreve:

Recuerdo a Paulo con inmenso cariño, pero también como aquel que intentaba con cada vez mayores energias salvar la credibilidade de las actividades educativas en una época en que mi principal preocupación era cuestionarme las condiciones que modelan la 
educación en todas sus formas, incluída la conscientización, o el psicoanálisis, o cualquier otra cosa. (Illich, 2013, p.168).

Assim, acreditamos que há indícios de que, a partir de certo momento, Paulo Freire e Ivan Illich caminham por interesses teóricos bem distintos, provavelmente em função de certa "captura" do pensamento de Freire. Enquanto Illich se concentrava em criticar aquilo que a sociedade, a tecnologia da escola, as instituições etc. fazem e "comunicam" para as pessoas, especialmente no fortalecimento da relação de dependência e do mito de que as pessoas necessitam ser ajudadas para terem uma melhor compreensão da realidade, ou que elas precisam ser ancoradas a se preparar para a existência ou para a vida (Illich, 1992), Paulo Freire está cada vez mais voltado em como "salvar a credibilidade das atividades educacionais existentes", ou seja, "como reformar instituições como da modernidade, tais como a escola" (Illich, 1992).

\section{Referências bibliográficas}

Câmara, D. H. (1968). Revolução dentro da paz. Rio de Janeiro: Editora Sabiá.

Cardoso, F. H. \& Faletto, E. (1985). Dependência e Desenvolvimento na América Latina. Rio de Janeiro: Zahar.

Che Guevara, E. (1961). Discurso del Comandante Ernesto Che Guevara en la quinta sesion plenária del Consejo Interamericano Económico y Social, en Punta del Este, Uruguay. Retirado de https://es.wikisource.org/wiki/Discurso_en_Punta_ del_Este,_Uruguay,_8_de_agosto_de_1961.

Dussel, E. (1991). Filosofia de la liberación desde la práxis de los oprimidos. Revista Libertação-Liberación 2, 33-49. Retirado de https://issuu.com/ricardo2p/docs/ liberta o-liberaci_n___antiga__-_ed0ba2621bea 48

Dussel, E. (1995). Filosofia da Libertação: crítica à ideologia da exclusão. São Paulo: Paulus.

Freire, P. (1983). Pedagogia da Esperança: um reencontro com a Pedagogia do Oprimido. São Paulo: Paz e Terra.

Freire, P. (1967). Educação como prática da liberdade. São Paulo: Paz e Terra.

Freire, P. (2002). Pedagogia da Autonomia: saberes necessários à prática educativa (21 ${ }^{a}$ ed.). São Paulo: Paz e Terra. 
Freire, P. \& Illich, I. (1975). Dialogo Paulo Freire-Ivan Illich. Buenos Aires: Ediciones Busqueda.

Gajardo, M. (2010). Ivan Illich. Recife: Editora Massangana.

Gaudio, A. (2012). Illich un profeta postmoderno. Brescia: Stampa Officine Grafiche 'La Scuola'.

Hoinacki, L. (2005). The Rivers North of the Future: The Testament of Ivan Illich as told to David Cayley, foreword by Charles Taylor. Toronto: Anansi Press. Retirado de http://www.pudel.uni-bremen.de/pdf/Hoinacki2005_ReviewTheRiversNorthOf.pdf

Illich, I. (1970). Sociedade sem Escolas. Petrópolis/RJ: Vozes.

Illich. I., Berlan, J. P., Bové, J., Brune, Decaillot, M., Goldsmith,., E., Latouche, S., Lemarchand, F., Llena, C., M`Baye, S., Perrot, M.D., Rahnema, M., Ravignan, F., Rist, G., Sajay, S. \& Zaoual, H. (2009). Desfazer o desenvolvimento para refazer o mundo (1a ed.).Vargem Grande Paulista: Editora Cidade Nova.

Illich, I. (2008a). Obras reunidas I. México: FCE.

Illich, I. (2008b). Obras reunidas II. México: FCE.

Illich, I. (2013). Conversaciones con Ivan Illich. Madrid/Espanha: Enclave de Libros.

Lemmerer, E. (2009). Examining a sample of the American-Mexican Scientific Cooperation in the 1960s: a social network analysis of the CIDOC-Network. (PhD Thesis). University of Vienna, Vienna, Austria. Retrieved from http://othes.univie. ac.at/6734/1/2009-09-24_0305546.pdf

Marcuse, H. (1978). Razão e Revolução. São Paulo: Paz e Terra.

Mitcham, C. \& Hoinacki, L. (2002). The Challenges of Ivan Illich: a collective reflection. New York: State University of New York Press.

Kierkegaard, S. (2012). Migalhas Filosóficas. Porto: Relógio D’Água.

Paquot, T. (2012). Introduction à Ivan Illich. Paris: Éditions La Découverte.

Robert, J. (2012). Centro Intercultural de Documentación (CIDOC). Recuparado de http://www.ivanillich.org.mx/8cidoc.pdf

Silva, A.G.F. (2013). Freire Internacional: experiências constitutivas e alguns modos de recepção ao pensamento freireano no mundo. In C., Pereira, M. Sabbatini \& R. Voss (Orgs.), Paulo Freire em Debate (1 ${ }^{\mathrm{a}}$ ed., pp.39-62). Recife: Editora Universitária UFPE.

Torres, C. A. (2005). Os mundos distorcidos de Ivan Illich e Paulo Freire. In A. Teodoro, C. A. Torres (Orgs.), Educação Crítica e Utopia: perspectivas para o Século XXI (pp.83-97). Porto: Edições Afrontamentos.

Zaldívar, J. I. (2012). Las teorias de la desescolarización: cuarentas años de perspectiva [Versión eletrónica], Revista Historia Social y de la Educacíon, 1(1), 28-57. 